\title{
ENGINEERS TEACHING ENGINEERING COMMUNICATION: INTEGRATING DISCIPLINARY EXPERTISE INTO THE ENGINEERING COMMUNICATION CURRICULUM
}

\author{
Kathleen Denbeigh, Ali Vahit Esensoy, Penny Kinnear, Jason Li, Wilson Ma, Michelle MacArthur, Asmaa \\ Maloul, Mario Milicevic, Aaron H. Persad, Farzan Sasangohar, Deborah Tihanyi, Liang (Leon) Yuan ${ }^{l}$ \\ Engineering Communication Program, University of Toronto \\ k.denbeigh@utoronto.ca, ali.esensoy@utoronto.ca, penny.kinnear@utoronto.ca, jason.li@utoronto.ca, \\ wilson.ma@utoronto.ca, michelle.macarthur@utoronto.ca, asmaa.maloul@utoronto.ca, mario.milicevic@utoronto.ca, \\ aaron.persad@,utoronto.ca, f.sasangohar@utoronto.ca, deborah.tihanyi@utoronto.ca, leon.yuan@utoronto.ca
}

\begin{abstract}
The Engineering Communication Program at the University of Toronto has recently begun using engineering graduate students as Communication Instructors (CIs) in the Mechanical Engineering portfolio courses and our work in the Mechanical and Industrial Engineering capstone design courses. The move was an attempt to bridge the discipline chasm between communication and disciplinary expertise; this paper begins to document the impact of this interdisciplinarity. Through an analysis of narratives of CI experiences using Engeström's model of activity theory, we narrowed our focus to an exploration of the changing rules and division of labour that occurred over the duration of the courses. We found that while students and CIs bring different understandings of rules and division of labour to the work, these elements can be changed-and that affect plays a key role in the changes.
\end{abstract}

Keywords: communication, interdisciplinarity, activity theory, narrative, capstone

\section{INTRODUCTION}

The Faculty of Applied Science and Engineering at the University of Toronto has had a dedicated unit devoted to the teaching of communication since 1995. In September of 2011 two full-time lecturers in the Engineering Communication Program (ECP) assembled a team of 14 graduate students as Communication Instructors (CI) for four communication courses in Mechanical and Industrial Engineering. Historically, communication instruction has been handled by instructors (full and part-time) with humanities or social science backgrounds. The 2011 team comprised primarily engineering graduate students. At the
University of Toronto, engineering graduate students traditionally work as Teaching Assistants with engineering content courses. In their role as CIs, they were asked to take a different perspective and position vis-à-vis the deliverables required of students. An engineering CI must focus on the rhetorical decisions students make with regard to audience, genre and purpose as well as the engineering content. It is important to note that while the engineering $\mathrm{CI}$ is primarily responsible for the rhetorical aspect of the communication, the engineering content is always present in any consideration of the student's work. The lack of first-hand engineering disciplinary knowledge - and the credibility that comes with it-has, at times, hindered buy-in from students and faculty alike with regard to communication deliverables. We were interested to understand what impact, if any, the change from primarily humanities/social sciencegrounded instructors to engineering-based instructors would have on student engagement with and valuing of the communication courses. This paper will attempt to describe, primarily from the CI's perspective, that experience, look at pedagogical implications and suggest directions for further research. We will use activity theory, particularly Engeström's expanded triangle [2], as a heuristic to understand the teaching/learning relationship between the students and the CIs.

\subsection{Background}

What began as Language Across the Curriculum (LAC), with a mandate to teach communication within engineering courses (nine courses in four departments that first year), has developed into the Engineering Communication Program (ECP). ECP is now fully integrated into the core curriculum in all departments in the Faculty through joint communication and design

\footnotetext{
${ }^{1}$ See Appendix A for details on departmental affiliations of authors.
} 
courses, portfolio courses and stand-alone courses (in addition to running a variety of non-credit programs and a tutoring service). ECP now has a complement of five fulltime faculty, approximately twenty sessional faculty and more than a dozen graduate student CIs.

From its inception, ECP has had a core value of meaningful collaboration with engineering faculty in the development of curriculum-particularly critical as the majority of instructors come from non-engineering backgrounds. ECP instructors-many of whom have been with the program on average for more than seven years-bring expertise from different disciplines in the humanities and social sciences, as well as a strong commitment to teaching and learning in engineering. Nevertheless, in the past three years, ECP has begun to incorporate engineering graduate students as an integral part of the teaching team. This attempt to bridge the perceived discipline chasm between communication instruction and engineering instruction aims to create a more integrated program that appreciates and reflects the complex relationship between communication and the substance of communication. This integration is difficult to quantify, partly because of the diverse types of interactions with students that occur in the different courses. Neither do we have documentation that accurately describes different levels of integration that would allow us to make informed decisions about future goals. One reason for this paper is to begin to document this phenomenon.

As part of our attempt to understand the impact of making engineering graduate students CIs we will explore some of the key questions that come from our interdisciplinary teaching experience. These include the nature of the relationships between engineering CIs and students (as well as engineering CIs and non-engineering CIs).

\subsection{Communication Program and Mechanical and Industrial Engineering}

Our analysis of the experience is based on the reflections of the 14 CIs who engaged with Mechanical and Industrial Engineering (MIE) students in four different courses: a second year Mechanical Engineering portfolio course (MIE297), a third year Mechanical Engineering portfolio course (MIE397) and the fourth year Mechanical (MIE491) and fourth year Industrial (MIE490) capstone design courses. The second year portfolio course requires students to prepare a $\mathrm{CV}$ based on an analysis of a broad range of their academic and non-academic experiences. Using these experiences as a starting point, students then reflect on possible career paths, through a comparison of their current interests, skills, and knowledge with potential jobs in different industries or academia. In many ways this is a first step in bridging academic experience with real-world career possibilities. The third year portfolio, building on the CV and career path analysis, requires students to research specific jobs and/or graduate schools in order to prepare a job specific resumé and cover letter or statement of purpose. In the capstone courses teams of students work with a client, an academic supervisor and a CI on a yearlong design/engineering project. The teams have to produce a Problem Definition Statement, a Project Charter, a final report and a poster and accompanying presentation.

As Johri and Olds [4] point out in their examination of situated learning in engineering, efforts are recently being made to bridge the gap between the more familiar cognitive perspective of learning and the situative perspective of learning. Cognitive theories of learning understand that all learning and development occurs within an individual mind, affected by a number of internal and external variables. Sociocultural theory understands that learning occurs first on a social plane that leads the development of higher order cognitive functions. Our analysis of the CI experiences is grounded in Vygotsky's sociocultural theory (SCT), specifically activity theory [6]. Vygotsky understood learning led cognitive development. An individual first learns in interactions with others using socially created symbolic (e.g., language, symbol systems) and material (e.g., computers, scales, rulers) tools. Through processes of imitation and conscious attention, the individual internalizes this initially socially mediated learning and thus develops higher cognitive functions, including abstract concepts. For example, the CIs working with capstone students mediated the students' learning of communication concepts of audience, genre and purpose in their face-to-face meetings with the students.

Vygotsky died before he could completely develop his idea of activity theory. He wanted to show human cognition in relationship with human physically and psychologically motivated activity. ${ }^{2}$ A. N. Leont'ev attempted to describe the dynamic relationship between the individual and the social norms, institutions and practices. He proposed three layers: activity-motivation, action-goal and conditions-operations. (See Daniels, Vygotsky and Research, chapter 6 for concise explanation of the development of activity theory from Vygotsky to Engeström [1]). Working from Vygotsky, Leont'ev and others' work, Yrjö Engeström developed a model of activity theory that has become known as the expanded triangle or second generation activity theory. In further development of the model he has created networks of these triangles or third generation activity theory. (See Chapter 1 in Perspectives on Activity Theory [3].) We

\footnotetext{
2 Activity here refers to the Russian term dejatel'nost. According to Ryle [5], "The concept of activity is poorly rendered by the English word; in activity theory the implication is of high-level, motivated thinking, doing and being of an individual in a given social context."
} 
have used Engeström's expanded activity triangle and activity network as a heuristic and analytical framework.

Engeström expanded the initial triangle that represented the relationship between an individual, a learning object and the symbolic and material means that mediated reaching that object. Engeström's expanded triangle made the social relationships more explicit (see Figure 1). Engeström used 'outcome' in his expanded triangle to represent the physical manifestation of the object. In our case, the different deliverables in each course constitute the outcomes. In MIE297, for example, the $\mathrm{CV}$ would be one outcome. In this example, the subject is the student. The object refers to the student's conceptual understanding of the significance of his/her

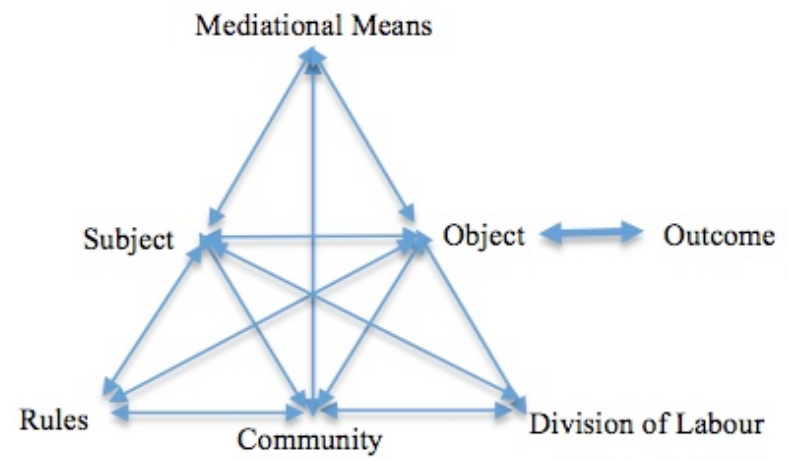

Figure 1: Engeström's Expanded Triangle

learning and experiences in relationship to the profession of engineering. The Community refers to the group of people the subject is engaged in the activity with-in this case, all of the second year students in Mechanical Engineering trying to make sense of their experiences for a CV. Mediational Means are all of the symbolic and material things that individuals use to accomplish their outcomes - for example, workshops, meetings with CIs and artefact analysis worksheets. Rules are the explicit and implicit rules that govern interactions with others and the material objects used. For example, an explicit rule for students and CIs may be to always use University of Toronto email for correspondence. The division of labour refers to who is responsible for the production of what in the interaction. For example, a student will create a draft of his/her $\mathrm{CV}$ and the $\mathrm{CI}$ will evaluate and provide feedback.

While it must be understood that none of the points in Engeström's expanded triangle are discrete, in order to limit the scope of this paper, we are concentrating our analysis on the rules and division of labour. We understand that the CI, the students and in the case of the capstone courses, the supervisor and the client, have a shared object. In the case of the Portfolio courses, the CI and the students share the object. However, students and the engineering and non-engineering CIs do not bring the same sets of rules or understandings of the divisions of labour to the activity or the tasks of the activity. We are interested in understanding how the different sets of rules and understandings of the division of labour interact and usually create new sets of rules and divisions of labour. It must be noted that although we did not seek to examine the role of affect, it is present and thoroughly entwined in all of the teaching/learning contexts. Understanding this interaction will contribute to the development of our pedagogy, our curricula and the mediational means we employ in pursuit of the shared objects and outcomes.

\section{METHOD}

This is an emergent research project, part of a larger endeavour to examine and understand teaching/learning in the ECP. The method is grounded more in qualitative inquiry than quantitative. We began by brainstorming with the MIE CIs possible ways of investigating the practice of employing engineering graduate students as Communication Instructors.

Our data consist of short narratives of CI experiences in their respective courses (see Appendix B), activity theory analyses of their individual narratives/experiences, and recordings of the discussions of the narratives, analyses and drafts of this article. As a caveat, we recognize that our data is incomplete as we did not ask students to describe their experiences in the courses or what they understood to be the rules and the division of labour. For this preliminary investigation we have only our CIs' interpretations, based on their interactions with students, of the students' understanding of the rules and the division of labour.

A cursory review of the narratives revealed several themes (e.g., mentoring, strategies such as students identifying errors, problems, conflict resolution, and relationships) but more importantly, the complexity of the teaching/learning interactions. At this point, we decided to limit our analysis to the Rules and Division of Labour categories from Engeström's expanded triangle. CIs were then asked to write down what they understood to be the rules and division of labour they brought to the different teaching/learning activities and what, if any, new rules or divisions of labour developed. These were gathered and analysed to yield examples of the rules and division of labour the CIs brought, the rules and division of labour they observed the students bring and the new rules and divisions that either emerged through practice or were negotiated.

\section{RESULTS: RULES AND DIVISION OF LABOUR}

Figures 2 and 3 (next page) illustrate the perceptions of rules and divisions of labour, respectively, from both the CI and student perspectives, both at the beginning of the 
course (before) and towards the end of the course (after). The text above the dashed diagonal line in each square is what is understood at the beginning of the course; text below the line reflects changes after a meeting or series of meetings.

\subsection{Rules the CIs bring}

The CIs identified as one source of explicit rules for themselves their contracts that set out the number of hours for which they would be paid, the number of required meetings with students and/or supervisory staff, the syllabus or course guide and the rubrics and the marking time allotted per assignment. The CIs assumed the rules for students included reading all instructions, including on-line instructions, attending the appropriate workshops, lectures, and/or help sessions, being prepared for meetings, completing and submitting assignments on time or prior to face-to-face meetings. Aaron was explicit in his instructions for preparation (expectations shared with other CIs), "Before scheduling a meeting, I requested that each team send me their document so that I could review. Additionally, I asked teams to highlight areas in the document that they would particularly like my feedback on." CIs also expected each student would participate in the sessions by, as Asmaa stated, “...talk[ing] out loud and evaluat[ing] his/her analysis."

In addition the CIs identified implicit rules for their interactions with students. Mario stated part of this as, "[i]t is the role of the CI to teach students to independently identify poorly communicated ideas, and inspire them to think about the importance of technical

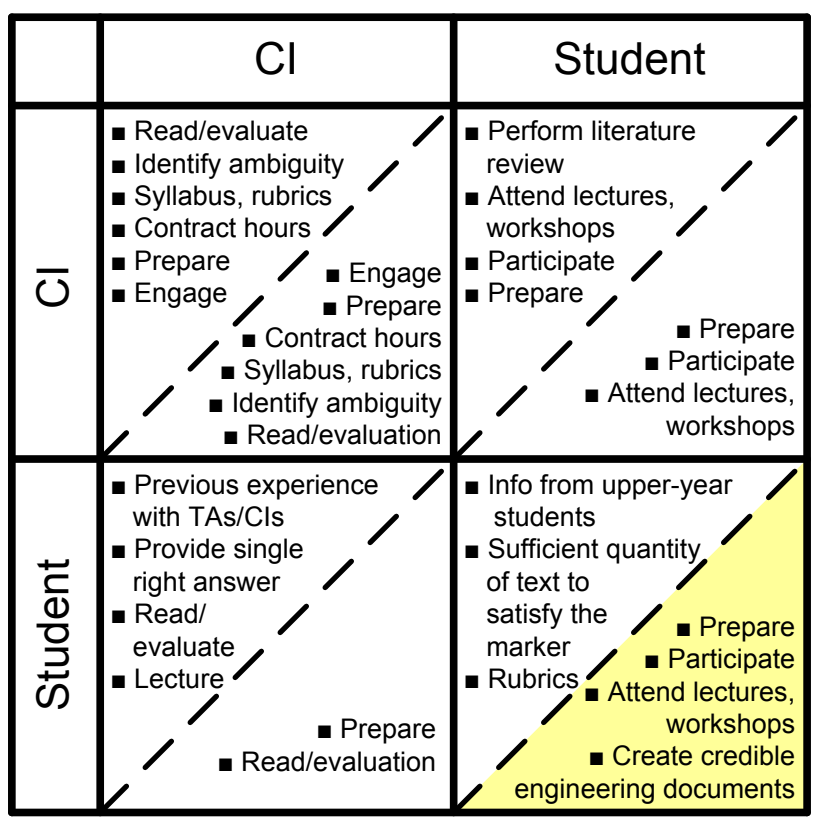

Figure 2: Rules from both perspectives, before and after clarity." Other rules included being attentive and engaging students, reading, evaluating and correcting student work, preparing for student meetings, identifying areas of technical ambiguity and claims in need of support, honing in on student needs, probing and questioning and not lecturing.

CIs also identified the regular benchmarking sessions we held before meeting students to discuss or mark a deliverable as critical for providing a collective rulebook for those activities. In addition, especially with the capstone courses, CIs found that some participation in the workshops and help sessions contributed to that collective rulebook.

\subsection{Rules that students bring}

Students brought a set of rules for themselves and a set they expected the CI to adhere to. CIs reported their initial impression of students' understanding of the rules was laid out in the assignment instructions, the syllabus or course guide and the rubrics used to evaluate the assignments. The CIs learned that this was not always the case. In addition there were some implicit rules that came from information students had gleaned from upper years, classmates or graduates, previous experiences with a CI and assumptions about what constituted a 'good' engineering document. Perhaps one of the most interesting (and strongest) was the implicit rule that there was always a right or wrong answer for every assignment.

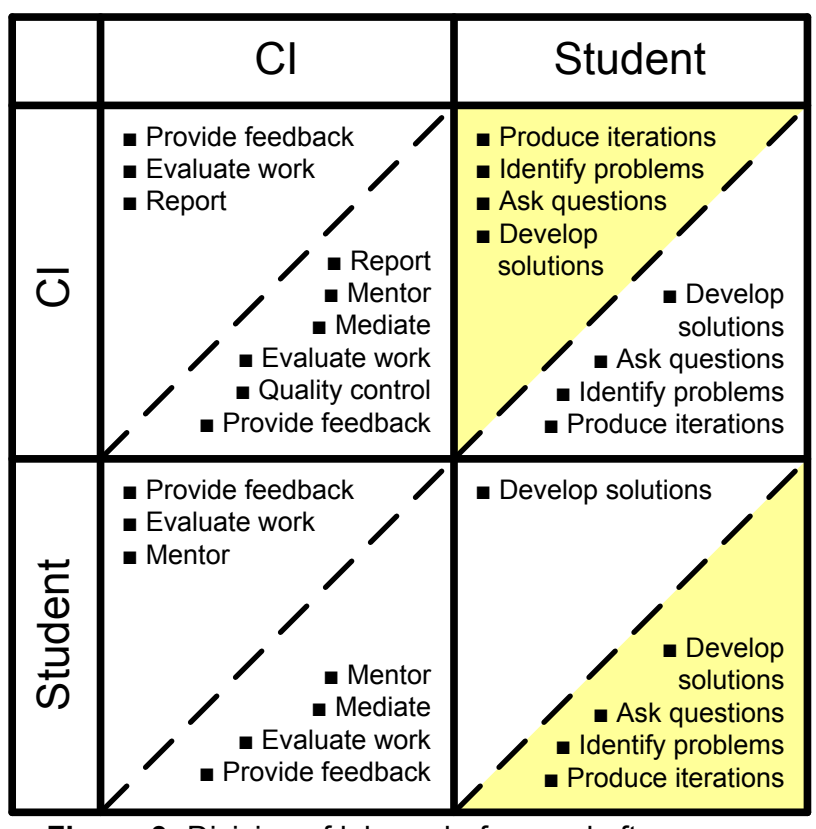

Figure 3: Division of labour, before and after 


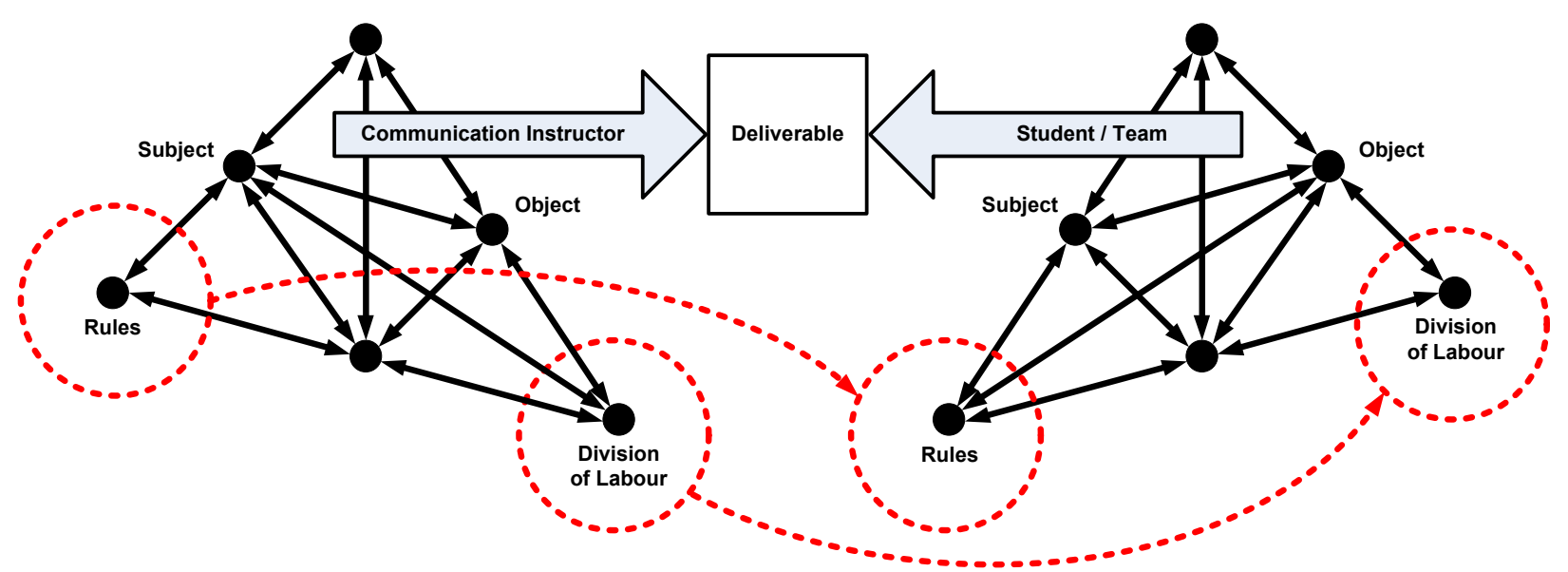

Figure 4a: Cl-Student Rules \& Division of Labour BEFORE

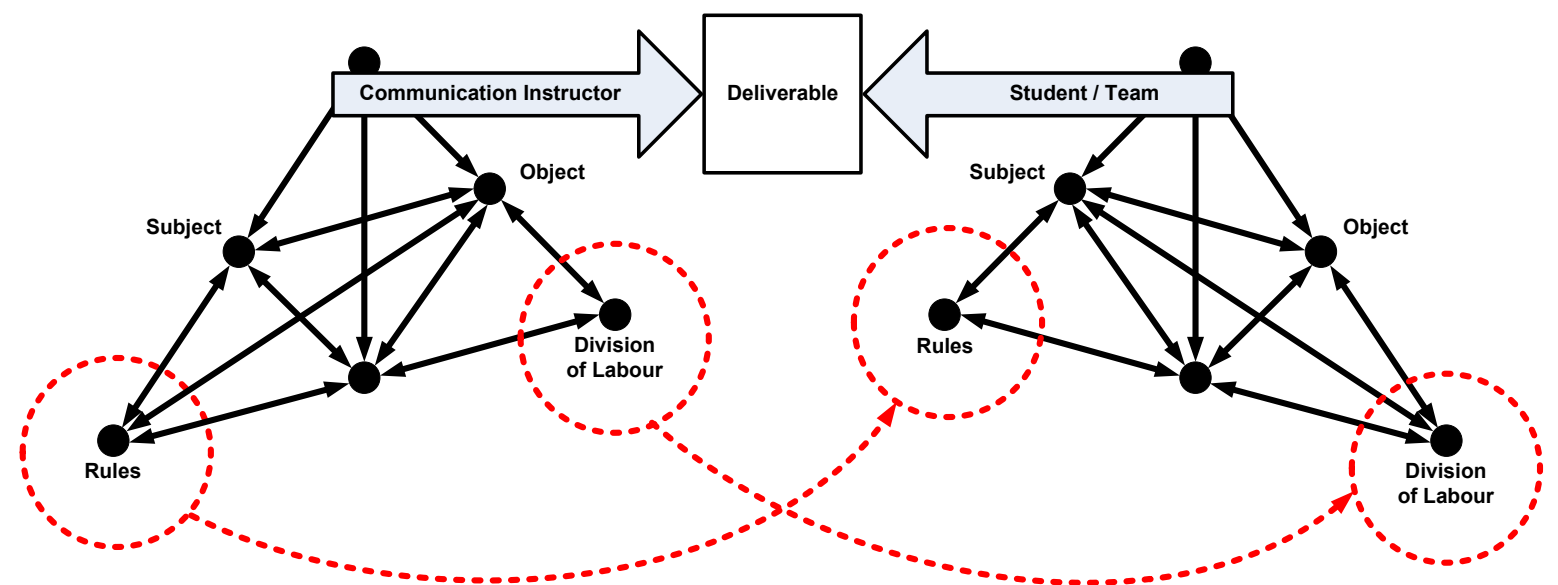

Figure 4b: Cl-Student Rules \& Division of Labour AFTER

\subsection{Division of Labour}

Once again, on the basis of the CI observations and experience, most students had a narrow sense of the division of labour - the student creates the content and the CI evaluates, corrects and provides feedback on whatever the students created.

CIs initially shared this view of division of labour where the student produces work and the CI evaluates whatever has been produced, primarily by indicating what is correct and incorrect or indicating errors and gaps in the product. Some of the CIs included a degree of 'quality control' with regard to students' performance compared with industry standards. Both students and CIs assumed an uneven distribution of power in the division of labour. The students had very little power while the CIs had a great deal, although the CIs did see there was a further division of labour. The CI was responsible for evaluating and meeting with students but also reporting student progress (or lack thereof) to the ECP supervisors.

\section{DISCUSSION}

The CIs' narratives and reflective conversations have allowed us to see that both the rules and the division of labour were not static but in the meeting context were negotiated or rewritten to better serve the emergent goals of that particular interaction. For example, Ali found that students did not follow the rule of coming to a meeting with a clear agenda. The rule was changed with the students: students were expected to discuss the questions raised by Ali. A further modification emerged after the first meeting-one team member was put in charge of taking notes. From Vygotsky's perspective, we can understand the interaction, at least partially, as the enactment of a zone of proximal development (ZPD), where a more knowledgeable peer provides contingent support that allows the student to successfully complete a task first in the presence of that support and then incorporate that support into the his/her own repertoire of concepts/knowledge. The negotiation of new rules and new divisions of labour were part of 
the creation of ZPD activity. That activity provided affordances for learning, for both the students and the CIs. This movement is particularly visible in Wilson's report of students telling him how they had adopted his technique of role-playing critiques of their documents before a meeting with him. Other CIs reported how students began to identify gaps, lack of specificity or clarity in their documents and propose solutions with less and less CI guidance. Students, in becoming more active participants in the evaluation or critiquing process, displayed their development with regard to the production of required documents.

It is also important to include in this discussion of rules and division of labour, affect and power. Throughout the narratives, the discussions and even the analyses, affective references abound. CIs mention their own and student frustration, confusion, satisfaction, tension, credibility, respect, alliance and so on. Changes in the division of labour often allowed for a shift in the balance of power between CIs and students reflected in new sets of rules. At the start of the process (see Figure $4 \mathrm{a}$, previous page), CIs were more focused on division of labour, and less on rules while students were more focused on rules and less on division of labour. The shift over the courses (see Figure 4b, previous page) brought both rules and division of labour into greater balance, and was often accompanied by a shift in the relationship. That relationship change was often characterized by the CIs as a move from evaluative to mentoring, from a vertical hierarchical relationship where the CI was limited to evaluating the content the students created to one that was a more horizontal relationship where the $\mathrm{CI}$ and the students collaborated to evaluate and even create content. This realignment was manifested in different ways (not necessarily true of all students) that included:

1) student preparation of questions prior to a meeting

2) student participation or engagement in meetings by discussing probes from the CI

3) students taking the lead in analysing the documents under review

4) students identifying problems, spotting weaknesses in documents

5) students reporting inconsistencies or conflicts among the expectations of different stakeholders

While the hierarchy was not completely flattened, CIs described the new mentoring relationship as more collegial and collaborative - and one that often extended beyond the evaluation of course deliverables. Affect is at work here as well. CIs felt their experiences contributed to their credibility with the students. The one-to-one meetings contributed to this relationship as well, especially in contrast with the large classes and little or no one-to-one interaction with other professors and instructors. Some of the CIs used their own engineering and industry experiences in their conversations with students. The CIs found their ability to critique an engineering idea and relate that to how it was expressed enhanced their credibility with the students.

However, not all the CIs shared the same engineering background as their students, and one in particular, Michelle (a Ph.D. candidate in Drama), noted that she used her experience and expertise in the communication skills needed to effectively communicate with different audiences to position herself as valuable and credible. Her students had no problem accepting that. Although engineering experience may predispose students to view a CI as credible, it is not the only criterion-reminding us that we need to consider the contribution of differing perspectives when considering the role of experience.

It is interesting to note that the verbs the CIs used to describe their interactions included mentor, advise, assist, engage, guide, or support, in contrast to the verbs implied by the initial student expectations of meetingscorrect, fix, mark. References to any evaluation were usually in the context of industry standards or practical experience. One of the CIs noted that this shift, including the language of evaluation, going from right/wrong answers to collaborative identification of strengths and weaknesses, often in reference to specific industry practices, put them in the position of mentor and seemed to increase their credibility with the students. In fact, mentor was most often repeated in our discussions and the analyses CIs did.

\section{CONCLUSION}

Our description of the CIs' experiences through a focus on the rules and division of labour provides part of a picture in our first attempt to understand the implications of using engineering graduate students as communication instructors. Our focus on the rules and division of labour indicate at least three important points. First, the rules and assumptions about the division of labour that students and CIs bring to the context are not usually shared nor are they necessarily the best ones in the teaching/learning context. Second, these elements can be changed, although initial efforts may be met with resistance. Third, affect - and how it reflects power - is not just a variable in the learning process but an integral part of teaching and learning.

Further research that includes the students, and in the case of the capstone courses the supervisors and clients, needs to be pursued. A careful consideration of the mediational means used by students, CIs, clients and supervisors will contribute more to our understanding of the teaching and learning in these particular contexts. 
We also see implications for the use of activity theory, both to guide the design of future research and our analysis of the complex interactions of people with other people, signs and tools.

\section{References}

[1] Harry Daniels, Vygotsky and pedagogy. London: Routledge, 2001

[2] Yrjö Engeström, "Activity theory and individual and social transformation," In Y. Engestrom, R. Miettinen \& R.-L. Punamäki (Eds.), Perspectives on activity theory (pp. 19-38). Cambridge: Cambridge University Press, 1999

[3] Yrjö Engeström,.., Reijo Miettinen,, \& Raija-Leena Punamäki, R.-L. (Eds.), Perspectives on Activity Theory. Cambridge: Cambridge University Press, 1999

[4] A. Johri and B. M. Olds, "Situated engineering learning: Bridging engineering education and the learning sciences," Journal of Engineering Education, 100(1), pp. 151-185, 2011

[5] Anthony Ryle, "Object relations theory and activity theory: A proposed link by way of the procedural sequence model," In Y. Engeström, R. Miettinen \& R.-L. Punamäki (Eds.), Perspectives on activity theory (pp. 407-418). Cambridge: Cambridge University Press, 1999

[6] L. S. Vygotsky, Thought and language (A. Kozulin, Trans.). Cambridge, MA: The MIT Press 1934/1986, 287 pp.

\section{APPENDIX A: ADDITIONAL INFORMATION ABOUT THE AUTHORS}

The Communication Instructors who contributed to this paper are graduate students in a number of departments. Listed below are their degree programs, departmental affiliations, areas of expertise and courses in which they were involved this year (MIE297 - second year Mechanical Engineering portfolio; MIE397 - third year Mechanical Engineering portfolio; MIE490 Industrial Engineering Capstone Design; MIE491 Mechanical Engineering Capstone Design):

- Kathleen Denbeigh

- MASc candidate, Biomedical Engineering (Biomechanics)

- MIE297, MIE397

- Ali Vahit Esensoy

- $\mathrm{PhD}$ candidate, Industrial Engineering (Healthcare)

- MIE297, MIE397, MIE490, MIE491

- Jason Li

- PhD candidate, Pharmaceutical S. (Controlled Drug Delivery)

○ MIE297, MIE397, MIE491
- Wilson Ma

○ MBA candidate, Management (Strategy and Finance)

O MIE297, MIE397, MIE491

- Michelle MacArthur

$\circ \mathrm{PhD}$ candidate, Drama (Feminist Theatre)

O MIE297, MIE397, MIE491

- Asmaa Maloul

$\circ \mathrm{PhD}, \quad$ Biomedical Engineering (graduated April 2012)

O MIE297, MIE397, MIE491

- Mario Milicevic

O PhD candidate, Electrical \& Computer Engineering (Electronics)

O MIE297, MIE397, MIE490, MIE491

- Aaron H. Persad

O $\mathrm{PhD}$ candidate, Mechanical Engineering (Thermodynamics and Kinetics)

○ MIE491

- Farzan Sasangohar

O $\mathrm{PhD}$ candidate, Industrial Engineering (Human Factors)

○ MIE490, MIE491

- Liang (Leon) Yuan

O PhD candidate, Electrical \& Computer Engineering (Photonics)

O MIE297, MIE397

Penny Kinnear (Lecturer) and Deborah Tihanyi (Senior Lecturer), Engineering Communication Program, coordinate communication in Mechanical and Industrial Engineering.

\section{APPENDIX B: CI Stories}

\section{B.1 Aaron Persad}

As a CI in MIE491, I provided guidance to ten teams on how to effectively communicate ideas to their supervisors and clients. I met with each team three to four times over the eight-month duration of the course, before each major document was due. I requested that each team send me their work in advance and asked them to highlight areas in the document that they would particularly like my feedback on. I reviewed the document before our meeting and made a list of items that I wanted to discuss. I noted several common issues with which teams struggled, such as structure and focus.

I wanted teams to be able to spot the issues in their documents themselves. So, I asked them to read certain paragraphs they had written and to identify how they 
could be improved. Many were able to point out issues such as wordiness, or lack of background information, etc. It was important to me to engage the students during the meetings and not just lecture to them on how to improve their writing-I believe this increases their investment in the process. In order to address issues such as document structure, I would ask teams to describe their project. Then I would ask three or four "why" questions; after responding to each "why", the students gave simpler and clearer descriptions of their work, sometimes to the point where an entire section of wandering ideas was condensed into three or four sentences that flowed logically. After having gone through one or two of these examples with them, I provided students with a marked up copy of their document and told them to apply the same method to fix issues within highlighted paragraphs.

I believe that my role as CI in a fourth-year capstone course is to teach students how to identify and fix issues with their writing. By addressing questions about their work, students unwittingly spot weaknesses and work out a solution without needing me to walk them through it. This is an important skill to develop, and I hope they continue to apply it in their careers. Additionally, having read through twenty different documents and writing styles, I've realized that my own writing suffers from the common issues I've identified with my students. I can now review draft manuscripts and ask myself "Why is this paragraph or sentence important?" and come up with more concise ways of writing.

\section{B.2 Asmaa Maloul}

In MIE297, each student submitted 15-25 worksheets, each analyzing a particular experience or artifact from a course, an extracurricular activity, or a job to demonstrate specific skills, knowledge and/or personal characteristics. Prior to our meeting, each student was required to submit their worksheets online.

Through my experience as a TA I find students to be more responsive to my feedback when they can identify the mistakes or the gaps in their work by themselves. I used this approach with students in MIE297. At the beginning of the meeting I opened the worksheets on my laptop and I asked students to walk me through his/her analysis. Since we had only 30 minutes for the meeting, I asked each of them to show me examples that demonstrate the three most important skills in their opinion. Students were able to take control over the way they wanted to present their worksheets and to evaluate their analyses as they explained them. This allowed me to ask them questions as they talked, guiding them to identify their weaknesses and strengths. Most students were able to recognize the gaps in their knowledge or skills and try to come up with solutions. Once they identified the problem, I provided some direction on possible ways they can develop solutions.

\section{B.3 Mario Milicevic}

At the University of Toronto, every undergraduate engineering student is taught that the perception of a good engineering idea is deeply related to the technical communication and presentation of that idea. Interestingly though, many students find this to be extremely obvious, and thus, often disregard it. As a result, such thinking often produces mediocre technical documents that unfortunately, describe truly outstanding ideas.

My mixed academic/industrial background has taught me that the presentation of an idea is significantly more powerful than the idea itself. In an undergraduate learning environment, it is the role of the CI to teach students to independently identify poorly communicated ideas, and inspire them to think about the importance of technical clarity. The following example illustrates a technique I used during my interim project meetings with $4^{\text {th }}$-year Mechanical Engineering capstone student design groups, in order to ensure that their projects were on track.

Before the meetings, each team was asked to submit a multi-page project charter report outlining their design ideas and methodology. Having read the project charter reports, the first question that I asked each team was to describe their project in a couple of sentences, and discuss the alternatives they considered and what methods would be used for evaluation. Each team provided stellar responses; however, when asked to identify exactly where each of their orally communicated points could be found in their technical document, they often admitted that it wasn't included or that it was too ambiguous. This typically sparked a discussion on succinct presentation of technical ideas and related techniques. Through these discussions, students would often realize that a table summarizing their design alternatives with evaluation methods was a very effective tool for decreasing the length of the their text, while simultaneously providing the reader with a very clear understanding of the ideas. Furthermore, the study of effective visuals, introductions, headings, and appendices allowed students to quickly highlight key areas of their reports that lacked technical clarity, and develop simple techniques to enhance the presentation of their technical ideas.

\section{B.4 Ali Vahit Esensoy}

For the past two years I have been involved as the head CI with the capstone design courses. The rules constituting capstone meetings between the CI and students are categorized in four groups: 
1. Formal rules are relatively concrete rules that are written as a part of the course planning process. These rules are known to all parties in advance and set the expectations for the course.

2. Conventions are unwritten expectations implied by the formal rules and the culture of the course/university/client.

a. Genre expectations come from similar reports/presentations made in university/industry.

b. Performance expectations are rooted in institutional as well as peer demands on the parties.

3. Procedural rules govern how the meetings are conducted, how the parties prepare for the meetings and how do they execute the decisions made during the meeting.

4. Social rules dictate how the power to is shared between the three evaluating groups of the course. They also dictate how the members will conduct themselves over the course of the meetings.

The nature of the meetings between the CIs and students changed over time as the rules and roles changed over the course of the year. One of the major changes that affected the dynamics of the CI-team meetings was the clarification of requirements. The purpose and requirements for the deliverables were not clear to the students despite the fact that they were included in the written course materials. This confusion caused students to believe that ECP's involvement was focused on more superficial aspects of communication (grammar, spelling, presentation) than the fundamental aspects (structure, argument). The problem definition statement meetings were affected by the tension between what the students expected the CIs to cover and recommend to be changed versus what the CIs chose to do.

At times, CIs were confused about where to draw the line in feedback between the structure and argument as they applied to the deliverables and the scientific merits of the content and design methods. The ECP workshops, CI benchmarking sessions and class communication clarifying the roles of the CIs effectively changed the formal rules as perceived by the students and the CIs. They also clarified the genre and $\mathrm{CI} /$ student performance expectations. This was especially important in clarifying that students are responsible for the iterative process and that CIs are coaches of this process, rather than pure assessors with right and wrong answers.

\section{B.5 Wilson Ma}

I want to highlight the development process of a pair of fourth year Industrial Engineering students in the Industrial Engineering capstone course. This was their first experience working with external clients and stakeholders in a live, financial-industry based project. The students were comfortable applying engineering tools to the project; however, since they were trained to constantly look for the "right" answer, they were unsure of whether they were heading in the right direction. I was able to draw upon my knowledge of the engineering project lifecycle from my undergraduate studies and my work experience in the financial services industry to support their project.

During meetings, we would run through their document and I would request further articulation of their approach, challenge their model and underlying assumptions, and work with them to explore other potential solutions. I role-played senior management in probing/poking holes from the highest level all the way to the very technical details of their analyses, and ensured these ideas were communicated at the right level of detail and jargon, etc. In this way, I would verify that their work was consistent with industry best practices.

Through time, I noticed this working relationship allowed for more creativity in the team's approach and experimentation with exploring different ways to meet stakeholder requirements. In addition, as my students knew that I would be looking for loopholes in their work each time we met, they were better prepared - they knew their project inside out and were ready to address tough questions. Towards the end of the term, these students told me that they role-played the communication instructor before meetings and tried to look for strengths and weaknesses within their projects first. For me, that was a great moment. I believe decoupling the mentor versus marker roles in part removes students from the mentality that they are 'searching for the correct answer to get the marks', and promotes more active learning.

My role was more complex than providing a simple one-dimensional textbook answer; rather it was a mentorship role that required active brain horsepower. Honing in on my students' needs gave me the ability to understand their specific circumstances and allowed me to best position advice in response to their concerns. I believe that from the student's point of view, constant interaction from someone who has 'been there done that' instilled a sense of confidence and motivated to keep the group moving forward.

I see this teaching style as not only effective at developing skills that will be valuable to them in their future career, but also my own. This experience showed me that there are greater levels of engagement as an 
instructor. The solution for each group - the framework, models and angle from which I approached them-was unique. The students also approached problems using perspectives and strategies I hadn't considered before.

\section{B.6 Michelle MacArthur}

Unlike many of my colleagues, I have no background in engineering, which presents me with some unique challenges in my work as a CI. I am not nearly as familiar with the subject matter as instructors who work and study in the field, my credibility is sometimes challenged by students who question my authority as a non-engineer, and the students with whom I work sometimes have different needs and expectations than those in my drama classes.

Though I have now been working in ECP for three years, MIE491 is the most technical course with which I have been involved, so reading the students' proposals and reports has been trying for me. I have to read some documents multiple times in order to gain a clear understanding of the nature of the project, and my Google search history now includes terms like "eddy current" and "high speed actuator." That being said, as CIs we continually stress to our students that they need to be communicating to multiple audiences, and that their clients may not share their technical expertise. So, I meet the first two challenges by taking advantage of my drama background: first, I am honest about my knowledge of the content and stress the importance of communicating to multiple audiences; I "sell" myself to the students by suggesting that they will meet people like me in industry, and that if I can understand their work, then most other people will as well. This allows me to build a case for strong communication skills, which I am well qualified to teach them (I stress this too), and to position my input as both valuable and credible. My experience as an actor also allows me to deliver this information confidently, even when I am not completely feeling that way.

As the resident "drama queen," I may be the odd person out, but I think my students have come to appreciate the perspective I can offer as an outsider. Conversely, my work with them has taught me how to communicate and adapt my teaching style to different audiences. I also now know what an eddy current is. 